\title{
Current potential and limitations of molecular diagnostic methods in head and neck cancer
}

\author{
Magdy E. Mahfouz $\cdot$ Juan P. Rodrigo $\cdot$ Robert P. Takes • \\ Mohamed N. Elsheikh • Alessandra Rinaldo • \\ Ruud H. Brakenhoff • Alfio Ferlito
}

Received: 1 December 2009/Accepted: 3 December 2009/Published online: 27 December 2009

(C) Springer-Verlag 2009

\begin{abstract}
Traditional diagnostic methods such as clinical assessment, histopathological examination and imaging techniques are limited in their capacity to provide information on prognosis and treatment choice of head and neck cancer. In recent years, molecular techniques have been developed that enabled us to get more insight into the molecular biological cellular pathways underlying tumor
\end{abstract}

This paper was written by members and invitees of the International Head and Neck Scientific Group (www.IHNSG.com).

M. E. Mahfouz

Department of Zoology, Kafrelsheikh University,

Kafrelsheikh, Egypt

\section{J. P. Rodrigo}

Department of Otolaryngology, Hospital Universitario Central de Asturias, Instituto Universitario de Oncologia del Principado de Asturias, Oviedo, Spain

R. P. Takes

Department of Otolaryngology-Head and Neck Surgery,

Radboud University Nijmegen Medical Center,

Nijmegen, The Netherlands

M. N. Elsheikh

Department of Otolaryngology-Head and Neck Surgery,

Tanta University, Tanta, Egypt

A. Rinaldo · A. Ferlito $(\square)$

Department of Surgical Sciences, ENT Clinic,

University of Udine, Policlinico Universitario,

Piazzale S. Maria della Misericordia, 33100 Udine, Italy

e-mail: a.ferlito@uniud.it

R. H. Brakenhoff

Department of Otolaryngology-Head and Neck Surgery,

VU University Medical Center, Amsterdam, The Netherlands progression and metastasis. Correlation of these molecular changes with clinical events has been explored. However, consistently useful markers have not been identified yet, although many promising developments are in progress. It may be expected that in the near future, molecular markers will be useful for clinical purposes. In this paper, an overview will be given of the several molecular techniques that may have potential to be introduced in clinical practice in the management of head and neck squamous cell carcinoma.

Keywords Molecular diagnostic techniques .

Molecular markers · Lymph node metastasis .

Head and neck cancer · Prognosis

\section{Introduction}

Despite major advancements in cancer diagnosis and treatment, the survival rate for patients with head and neck squamous cell carcinoma (HNSCC) has only marginally improved over the past few decades. Our ability to prognosticate HNSCC patients is especially poor owing to variations in the biological behavior of tumors and inadequacies of the present staging system. At present, histopathological features, such as tumor site, $\mathrm{T}$ classification, the presence and extent of nodal metastasis, tumor volume and thickness provide the most reliable tumor-related determinants of prognosis, and influence treatment in patients with head and neck cancer. On the basis of these clinical and pathologic parameters, the most likely clinical outcome can be estimated in an attempt to make the most appropriate decision for patient management.

Recent advances in basic research and genomics have improved our understanding of the molecular processes 
governing head and neck cancer progression [1, 2]. It could be expected that the identification of molecular signatures and understanding mechanisms of tumor progression may facilitate the identification of new predictive and prognostic markers and new therapeutic targets for the treatment of this cancer. In addition, these molecular markers might allow very sensitive detection of minimal residual cancer cells in the various compartments of the body. RT-PCR approaches have been described that allow the detection of a single tumor cell in 20 million normal white blood cells [3]. In 2005, Rodrigo et al. [4] reviewed the potential of the new molecular diagnostic methods in head and neck cancer. At that time, few of these methods were translated into improved patient care or better technology for molecular diagnostics. In the last years, the widespread use of high-throughput technologies (especially microarrays) has generated a considerable amount of information about the potential application of these techniques as predictive or prognostic markers. However, although the technological possibilities seem endless, the practical implementation of these assays in the clinic still appears to be some way into the future. Moreover, many of the approaches developed do have prognostic impact, but usually not to an extent that it can be used for the clinical management of the individual patient.

Therefore, in the present article, we review the emerging information in high-throughput ("molecular") diagnostic assays in HNSCC from a critical perspective.

\section{Molecular diagnostic techniques}

Currently, it is widely accepted that cancer arises as a result of the accumulation of genetic and epigenetic alterations in oncogenes and tumor suppressor genes, causing clonal evolution of the cells with most malignant phenotype. Some of these alterations occur specifically in the genes that play a crucial role in the normal behavior of the cell, but often these changes appear in less crucial sequences and are, therefore, a mere reflection of the genetic instability of the tumors [5]. Hence, tumor cells harbor specific clonal genetic changes that can be used as molecular markers for the detection of cancer cells in clinical samples. In addition to these tumor-specific genetic alterations, tissue-specific markers can also be exploited, but with two important considerations: (1) the marker should still be expressed homogeneously in the tumors derived from the tissue; and (2) the marker should preferably not be expressed in the clinical sample of interest. The choice of a particular marker or assay depends on the necessary sensitivity and specificity of the assay, the origin of the clinical sample, and the laboriousness of the assay [3].
The genetic analysis of cancers reached a crescendo with the completion of the Human Genome Project along with the development of high-throughput genome-wide analytic techniques. Nowadays, these encompass the complete sequencing of all protein encoding genes and high-resolution array methods that allow in identifying amplifications and deletions up to the 100 base pair level. These analyses have helped to shape our understanding of human malignancies generally, and head and neck cancers specifically.

Accurately identified biomarkers may provide new avenues for early cancer detection, and constitute targets for cancer risk assessment. Biomarkers are compromised by their insufficient diagnostic sensitivity and specificity; and are thus not used for definitive diagnosis, but as an auxiliary approach to assist in clinical decision-making. Emerging high-throughput technologies, including microarray and mass spectrometry, provide global information to observe genetic and proteomic alterations and to facilitate the discovery of new biomarkers with improved sensitivity and specificity. Moreover, the development of powerful bioinformatics methodologies has contributed to the measurement of thousands of gene expressions simultaneously [6-8]. Advances in proteomics and genomics have contributed to the understanding of the pathophysiology of neoplasia, cancer diagnosis and anticancer drug discovery. The powerful 'omics' technologies have opened new avenues towards biomarker discovery, identification of signaling pathways associated with cell growth, cell death, cellular metabolism and early detection of cancer. Analysis of tumor-specific "omics" profiles provided a unique opportunity to diagnose, classify, and detect malignant disease; to better understand and define the behavior of specific tumors; and to provide direct and targeted therapy [9].

\section{Molecular techniques for lymph node metastasis}

The presence or absence of metastatic disease in cervical lymph nodes is the only most significant determinant of the subsequent therapy and prognosis for patients with head and neck cancer [10]. Given the impact of nodal status on treatment and prognosis, accurate staging of cervical lymph nodes is critical. However, lymph nodes with micrometastatic deposits cannot be detected preoperatively with modern imaging techniques. Investigations, such as computed tomography, magnetic resonance imaging and the newer positron-emission tomography are relatively expensive for the average-income patient in many countries and still are unable to reliably detect tumor deposits smaller than about 3-5 mm [11]. Most reliably seems ultrasound-guided fine-needle aspiration cytology, but the 
limitations in sensitivity have limited widespread use for clinical decision-making. A new and promising development is sentinel node biopsy, but this already necessitates a surgical procedure. The limitations in staging have resulted in the elective treatment of the neck, usually by selective neck dissection in surgically treated patients, even in patients without clinical or radiological evidence of lymph node metastasis. Selective neck dissection adds limited, but not neglectable morbidity [12], but it is an effective treatment modality for early metastatic disease. Traditionally, the chance on occult metastasis is estimated depending on the site and the size of the primary tumor. Several other histopathological factors have been identified that correlate with a higher risk of occult metastasis, e.g. depth of invasion [13-16].

In two ways, molecular techniques may contribute to improvement of diagnostics. First, by better detection of micrometastasis and second by improving the assessment of the chance on clinically and radiologically occult metastasis based on the features of the primary tumor [17].

\section{Detection of micrometastasis}

The incidence of occult sub-pathologic metastases in patients with HNSCC has a mean incidence rate of $15.2 \%$ [18]. In 2005, Yoshida et al. [19] investigated immunohistochemically the presence of occult metastases in cervical lymph nodes from 24 patients with T2 N0 tongue cancer and found micrometastasis in $58 \%$ of the patients. Two lines of evidence suggest that routine light microscopic histologic examination of neck dissection specimens fails to detect a portion of these occult nodal metastases. First, recurrence rates of approximately $10 \%$ are reported in patients, who had histopathologically negative neck dissection specimens, suggesting that metastases were present, but not detected in the resected nodes [20]. However, recurrence can of course never occur in the resected specimen, hence the recurrence has to be was in non-resected nodes. So this phenomenon merely indicates inaccurate staging in $10 \%$ due to incomplete resection of all neck nodes. Second, retrospective studies using the more sensitive yet laborious and expensive technique of complete sectioning and immunohistochemistry of the lymph nodes have found that $8-20 \%$ of patients with HNSCC have nodal metastases that were not identified by routine histopathologic examination [18]. In accordance, Cote et al. [21] determined that the identification of regions of metastasis by hematoxylin and eosin (H\&E) staining of negative lymph nodes on histologic examination required the analysis of up to 144 slides/patients and, therefore, it is not surprising that regions of metastasis within the lymph node are not detected on routine histopathologic examination. Therefore, serial microscopic sectioning of the nodes may reveal micrometastases, but is impractical for routine use. Recently, there has been considerable progress in molecular diagnostics in these areas.

Several RNA-based markers were successfully used to detect lymph node metastasis in head and neck cancer. In 2005, Elsheikh et al. [22] prospectively examined 48 patients with squamous cell carcinoma of the oral cavity, with no palpable cervical lymph nodes who underwent an elective supraomohyoid neck dissection. The incidence of micrometastasis to lymph nodes was evaluated by pathological examination as well as by molecular analysis (CK20 mRNA expression). Of the 48 patients, 15 (31\%) by pathological analysis and $22(46 \%)$ by molecular analysis had lymph nodes positive for metastatic squamous cell carcinoma. By molecular analysis, $5(10 \%)$ of the 48 patients had involvement of sublevel IIB lymph nodes. Using molecular analysis, the authors concluded that clinically uninvolved sublevel IIB lymph nodes can be left behind in elective supraomohyoid neck dissections in patients with squamous cell carcinoma elsewhere in the oral cavity, but should be included whenever tongue is the primary site. In the same year, the same authors prospectively investigated 31 patients with squamous cell carcinoma of the larynx who underwent an elective lateral neck dissection [23]. The incidence of micrometastasis to lymph nodes in lateral neck dissection specimens was evaluated by nested reverse-transcriptase-polymerase chain reaction (RT-PCR) for cytokeratin 19 (CK19) and cytokeratin 20 (CK20), as well as by pathological examination. Nested RT-PCR for CK19 and CK20 mRNA presented similar results to each other, but these results differed from those of routine pathological examination. Of the 31 patients, 6 $(19 \%)$ by pathological analysis and $9(29 \%)$ by molecular analysis had lymph nodes positive for metastatic squamous cell carcinoma. By molecular analysis, only 1 of the 31 patients had involvement of sublevel IIB lymph nodes. Other investigators used the detection of CK14 mRNA by RT-PCR as a marker of nodal metastases; they found that CK14 RT-PCR is highly sensitive for detecting micrometastasis in lymph nodes that are negative by routine pathological examination, but with a relatively high falsepositive (50\%) [24] rate. To avoid this problem, Yamazaki et al. [25] determined p53 mutations in lymph nodes using mutant allele specific amplification (MASA) in 21 patients with oral squamous cell carcinoma. Of the 10 patients with pathologic pN0, 4 (40\%) were genetically positive; 44 (9\%) of the 476 lymph nodes diagnosed as negative by H\&E staining were found to contain DNA with the same mutation as detected in the primary tumors by the MASA method. In addition, they observed that patients with multiple or lower neck spread of micrometastases as detected by this DNA assay have a poor prognosis. A 
potential problem in the use of DNA markers might be that DNA is an extremely stable molecule and tumor-derived DNA might find its way to the lymph nodes. This same problem caused false-positive results when applied to the detection of minimal disease in histopathologically tumorfree surgical margins [3].

In addition at the RNA level, HNSCC-associated antigens such as the E48 (hLy-6D) antigen allows the detection of rare HNSCC cells in blood and bone marrow and, also in lymph nodes and lymph node aspirates [26, 27].

A successful novel molecular diagnostic method for rapid evaluation of lymph node metastasis in breast cancer was indicated by Tsujimoto et al. [28]. They developed a new intraoperative molecular diagnostic method, a onestep nucleic acid amplification (OSNA) to quantitatively measure CK19 mRNA expression. This assay consists of a sample preparation and rapid gene amplification by RT-LAMP (reverse-transcriptase loop-mediated isothermal amplification) — the whole process takes only $30 \mathrm{~min}$. In the same way, Ferris et al. [29] using quantitative reverse transcription-PCR (QRT-PCR) has identified four markers that discriminated between positive and benign nodes with accuracy greater than 97\%. These markers were PVA (pemphigus vulgaris antigen, also known as desmoglein-3), SCCA1/2 (squamous cell carcinoma antigen, neutral and acidic forms), PTHrP (parathyroid hormone-related protein), and TACSTD1 (also known as EPCAM). Moreover, one of these markers, PVA, discriminated with $100 \%$ accuracy between positive and benign lymph nodes. The authors have developed a rapid quantitative QRT-PCR assay for PVA that was incorporated into a completely automated RNA isolation and QRT-PCR instrument (the GeneXpert) developed for molecular diagnostic testing. The automated analysis with $P V A$ also provided perfect discrimination between benign and malignant lymph nodes, and was completed (from tissue to result) in about $30 \mathrm{~min}$, thus demonstrating the feasibility of intraoperative staging of HNSCC sentinel lymph nodes by QRT-PCR.

To develop a more efficient method for intraoperative genetic detection of lymph node metastasis in HNSCC, a total of 291 lymph nodes (59 patients) resected on SLN biopsy for cN0 HNSCC or neck dissection for $\mathrm{cN} 1 / 2$ HNSCC were diagnosed by OSNA method using GD-100 [30]. The OSNA assay could be completed within $30 \mathrm{~min}$ and the authors speculated that it showed high sensitivity and specificity and can be used as a novel genetic detection tool of lymph node metastasis in HNSCC patients.

The major problem of all of these methods is that they do not easily fit in the routine logistics of the pathological examination of the dissection specimens. Most molecular methods work only reliably on fresh or frozen tissues and require direct sampling from the surgical specimen. This is more laborious and not easily planned in daily practice.
Alternatively, when methods would be suitable for analysis on formalin-fixed paraffin-embedded samples, then additional cuts of the block need to be made. These molecular methods seem, therefore, most suited for rapid and sensitive analysis of subgroups of lymph node, such as the sentinel lymph nodes.

\section{Predictive tests for metastasis}

For decades, predictors for nodal metastasis have been sought, realizing that it would not be likely that a single marker could predict this event which is the result of very complex processes [17, 31]. However, numerous single markers have been studied which showed a significant correlation with nodal metastasis, with even very recent examples [32]. However, no consistently relevant marker, validated in larger series, has been established to date.

Recently, signatures have been identified for prediction of lymph node metastasis in patients with head and neck cancer based on the gene expression measurements in the primary tumor $[33,34]$. The potential clinical relevance of these signatures resides in the difficulties for currently diagnosing the absence of lymph node metastasis in patients with head and neck cancer. Many patients with a clinically negative neck receive inappropriate treatment due to difficulties in preoperative detection of metastases in the cervical lymph nodes [35, 36].

Roepman et al. [37] reported that their initially identified set of predictive genes for the detection of lymph node metastasis in patients with head and neck cancer is a subset of a larger group of predictive genes. Using a resampling approach, they have identified a large set of 825 genes that can be used for prediction of lymph node metastasis. Based on this group of genes, multiple predictive signatures can be made with high-predictive accuracy. This is in agreement with earlier observations [38] and for the head and neck lymph node metastasis profile, Roepman et al. [37] concluded that this is because there are many genes with a similar expression pattern across the sample collection. In contrast to other profiling studies, the predictive head and neck lymph node metastasis signature has a more stable gene composition, with a larger number of genes used in all tested predictors. Strikingly, exclusion of the most frequently occurring predictor genes could be compensated by increasing the number of genes included in the signature. Together, these analyses reveal that the most comprehensive set of predictive genes that can be included in further development of a diagnostic tool for the prediction of lymph node metastasis.

The identified expression signature has the potential to improve diagnosis and treatment of head and neck cancer, particularly by reducing the number of patients given 
unnecessary neck surgery. The molecular signature has been validated on an independent set of tumor samples to make sure that the signature was not over-fitted on the training samples and also works on new samples [34], as has been previously advocated [39]. Independent validation of this signature showed an accuracy of $100 \%$ for metastasis-free predictions with an overall accuracy of $86 \%$ for all samples. Importantly, no false-negative predictions were made. Current clinical diagnosis of these patients showed an overall accuracy of $68 \%$ and included five falsenegative predictions. The results of the validation set show the clinical potential of the signature. A large multicenter prospective validation study is required to confirm this potential before the signature can be applied in patient management, and currently carried out in the Netherlands.

Besides this study, several other HNSCC metastatic signatures have been published [33, 34, 40-43]. These HNSCC metastatic signatures were derived using several different profiling platforms and analytical approaches (i.e. supervised analysis of primary tumor signatures based on the association with the presence of lymph node metastases, comparison of immortal vs. mortal HNSCC samples, and comparison of metastases with paired primary tumors). These diverse study designs can explain some of the discrepancies seen in the direction of gene expression changes and strengthen the significance of the genes that are independently discovered in multiple studies. Similarities seen between all these studies when pathways, rather than individual gene products, were compared indicates that high-level systems analysis will likely be essential for the understanding and development of clinical applications from primary gene expression data.

A potential problem that needs to be solved is that specifically T1/T2 tumors in the oral cavity qualify for such a staging procedure, and the amount of tumor sample is then intrinsically limited. This might require that histological diagnosis needs to be carried out on frozen sections in the future or the methods should allow to use FFPE derived RNA. Alternatively, a profile might be derived on the basis of genetic changes. DNA-based methods work very reliably on FFPE specimens.

\section{Molecular techniques for prognosis}

Global genomic analyses have identified molecular subsets of HNSCC, which may have prognostic implications [2, $33,44,45]$. The challenge has been to reproduce prognostic gene signatures. For example, two independent groups have reported gene signatures that predict outcome in breast cancers using gene arrays, one including 70 genes and the other 76 genes [46, 47]. Interestingly, although both sets of genes have been validated in independent patient cohorts, there is relatively little overlap between the gene sets. Similarly, the use of individual and combined markers to predict outcome in HNSCC has shown conflicting results, as is well illustrated by the variable correlation between p53 status and outcome reported by different investigators [48-50]. The literature contains a plethora of reports describing single molecular markers for prognosis. Of these, few molecular markers have shown an effect that is independent of conventional clinicopathological parameters and strong enough to influence clinical decisions for the individual patient. In addition, most studies include only small numbers of cases and seemingly useful markers have only rarely been applied to a second sample set, using the same methodology to verify the results. So far, the majority of molecular markers evaluated have been correlated with a good or bad prognosis in different studies. Probably, this reflects the different treatments that the patients have had namely, surgery, radiotherapy or combinations. Factors, such as the overall treatment time, total radiation dose delivered, fraction size, and delay to treatment also influence the final outcome; hence, it is not surprising that studies utilising molecular markers have often given contradictory results. As mentioned, the introduction of microarray technology was expected to bring the power to identify molecularly defined subclasses of tumour, which may predict clinical behavior. However, at present, the differences between studies involving similar tumour types can be as striking as the similarities and our understanding of the biological relevance of these array profiles is unclear. In addition, it has been recently shown that differences in gene expression related to aggressiveness of HNSCC disease are highly site specific. Therefore, it is plausible that specific biological mechanisms underlying tumor aggressiveness are heavily influenced by the anatomic site of the primary tumor such that different mechanisms offer advantage only within the specific environment of a single anatomic site [2].

Several studies have used comparative genomic hybridization $(\mathrm{CGH})$ to categorize prognostic subgroups in HNSCC. Three of these studies define individual prognostic markers among a background of complex genetic aberrations identified by $\mathrm{CGH}$ using well-defined statistical methods [51-53]. These studies identified amplifications at $11 q 13$ and 3q26-27 as markers of outcome. The 11q13 amplification has been well studied, with well-characterized oncogenes, including cyclin D1, cortactin, FADD, and TAOS1 as putative targets for $11 \mathrm{q} 13$ amplification [30, 54-57].

Amplification at $3 \mathrm{q} 26.3$ has also been a topic of significant analysis, with several putative genes (including PIK3CA, PKC- ${ }_{l}$, LAMP3, and eIF-5A2) identified at this locus [58-62]. Similarly, gene array studies have delineated putative prognostic subsets that predict outcome 
$[33,44,50]$. Overall, studies using DNA-based assessment have been more reproducible than those that profile using mRNA-based gene arrays. Moreover, even though they are provocative, none of these studies have been validated sufficiently to allow use in routine clinical practice [63].

A very intriguing recent study indicated that HNSCCs might be classified on the basis of their genetic profile. It is well known that subgroups of head and neck cancer are caused by infection of the human papillomavirus and these tumors have in general a favorable prognosis. Importantly, these tumors are very distinct at molecular level [45, 64]. However in the tumors that are negative for HPV also two molecular subgroups are present, one with multiple genetic changes (high CIN) and one with hardly any genetic change (low CIN). This subclassification was related to clinical and etiological factors, and even prognosis [65], and might become highly relevant for the future.

\section{Molecular techniques for early detection of malignant disease}

Recently, the extraordinary progress in nucleic acid-based technologies has permitted the use of new diagnostic methods. Nucleic acid-based markers may prove to be valuable tools for early detection of cancer in asymptomatic individuals, for confirmation or exclusion of a cancer diagnosis that is based on suspicious, but non-diagnostic clinical material, for assessment of tumor burden in cancer patients, and for assessment of response to preventive approaches applied to healthy individuals who are at a high risk for developing cancer [66].

Two DNA markers are relatively established; tumorspecific p53 mutations and microsatellite alterations, which can be exploited not only as tumor markers in HNSCC, but also in many other tumor types [67-69]. K-ras mutations are relatively rare in HNSCC, which prohibits their use in molecular approaches. In other tumor types, $K$-ras mutations are often used as markers [3]. The major limitation of point mutations as molecular marker is that these need to be analyzed for every single tumor sample. In addition, the assays to detect these point mutations in a background of normal DNA are laborious and require a lot of validation. The major limitation of microsatellite markers is that these can only be analyzed in more or less pure populations of (pre)malignant cells. The relative imbalance of one allele versus the other is considered as allelic loss using cut-off points of $50 \%$. Hence, when more than $50 \%$ of normal DNA is present in a sample then they are always scored negative. All molecular markers have their pros and cons [3].

Saliva, the most accessible and non-invasive biofluid of our body, harbors a wide spectrum of biological analytes informative for clinical diagnostic applications. Park et al. [70] have previously shown that a transcriptome is found in saliva, and subpanels of these mRNAs can be used as oral cancer biomarkers. In 2009, Park et al. [71] measured the presence of microRNAs (miRNA) in saliva and determined their potential as an additional set of oral cancer biomarkers. A total of 314 miRNAs were measured using reverse-transcriptase pre-amplification-quantitative PCR in 12 healthy controls. Degradation patterns of endogenous and exogenous saliva miRNAs were measured at room temperature over time. Selected miRNAs were validated in saliva of 50 oral squamous cell carcinoma patients and 50 healthy matched control subjects. Two miRNAs, miR-125a and miR-200a, were present in significantly lower levels in the saliva of oral squamous cell carcinoma patients than in control subjects, and the authors claimed that saliva miRNAs can be used for oral cancer detection.

To explore the presence of informative protein biomarkers in the human saliva proteome and to evaluate their potential for detection of oral squamous cell carcinoma (OSCC), Hu et al. [72] collected saliva samples from patients with OSCC as well as from matched healthy subjects. The proteins in pooled whole saliva samples were profiled using shotgun proteomics based on C4-reversedphase liquid chromatography for pre-fractionation, and immunoassays were used for validation of the candidate biomarkers. Five candidate biomarkers were successfully validated using immunoassays on an independent set of OSCC patients and matched healthy subjects. A combination of these candidate biomarkers yielded a receiveroperating characteristic value of $93 \%$, sensitivity of $90 \%$, and specificity of $83 \%$ in detecting OSCC. The authors concluded that patient-based saliva proteomics is a promising approach to search for OSCC biomarkers. The discovery of these new targets may lead to a simple clinical tool for the non-invasive diagnosis of oral cancer.

\section{Discussion}

Recent studies reported that microarray analysis has the potential to change the diagnosis, classification and treatment of cancer [73, 74]. Genome-wide gene expression measurements have been used to identify expression signatures capable of estimating a patient's survival rate and treatment response $[75,76]$ and to predict the metastatic potential of primary tumors [34, 77]; such expression profiles or signatures are expected to improve treatment strategies by providing a more personalized therapy, based for example on disease severity [78, 79]. As yet, the majority of signatures are still in a developmental stage, and generally not strong enough to be used for clinical decision-making for the individual patient. Prospective 
validation of the first profiles has been launched at institutes in Europe and the United States [74]. These clinical trials are done on a large number of patients, require a great investment, and can only be carried out for profiles showing strong potential.

Despite the possible benefits, genome-wide studies for improvement of cancer diagnostics are currently being critically evaluated [38, 80]. Several microarray studies have identified gene sets capable of predicting a similar prognostic outcome, such as survival rate of breast cancer patients [42, 75, 77]. Interestingly, the overlap between the predictive gene sets from these different studies is limited to only a few genes. A recent analysis of microarray signatures found that the gene composition of expression signatures depends on the samples that were used for building the signature [38]. Although the instability in gene composition is not necessarily a negative property of signatures, it does not simplify the task of choosing which genes are the best candidates for designing a diagnostic predictor.

In addition, to justify the more laborious and costly gene signature as a classifier, it is not enough to show that it is more significant than traditional risk factors in a multivariate regression analysis, such as a Cox-proportional hazards model. For example, in breast cancer, Dunkler et al. [81] showed that the 70-gene signature from van't Veer et al. [79] gave a moderate, but not significant improvement in predictive accuracy in 234 patients from a validation study, when added to the following prognostic factors: age, nodal involvement, estrogen receptor status, and tumor grade. Although much of the clinical interest has focused on these gene signatures as predictive classifiers, they are, of course, of considerable interest scientifically as discovery tools, potentially identifying novel interventional targets.

\section{Conclusion}

Cancer and HNSCC in particular is the result of dysregulation of a complex system of molecular signaling pathways resulting from changes in DNA, RNA and posttranscriptional molecules. Integration of information from several different "omics" is needed for understanding of the complex biology of cancer. Despite a substantial research effort over 25 years, very few prognostic markers and predictive assays have been established in routine clinical oncology. Optimism and numerous significant correlations cannot disguise the fact that this field still needs to deliver on the promises. A major problem appears to be the lack of a critical and consistent research track for developing and testing candidate assays. Large collaborative networks together with more awareness of appropriate study designs and statistical methods will bring this field forward. The most important ingredient will be large wellconducted validation studies that will provide definitive evidence on the value of specific diagnostic assays. After validation, a future could be envisaged in which classification systems and prognostic models contain molecular information enabling improved treatment choices and better outcomes.

\section{References}

1. Perez-Ordoñez B, Beauchemin M, Jordan RCK (2006) Molecular biology of squamous cell carcinoma of the head and neck. J Clin Pathol 59:445-453

2. Belbin TJ, Schlecht NF, Smith RV, Adrien LR, Kawachi N, Brandwein-Gensler M, Bergman A, Chen Q, Childs G, Prystowsky MB (2008) Site-specific molecular signatures predict aggressive disease in HNSCC. Head Neck Pathol 2:243-256

3. Van Houten VMM, Leemans CR, Kummer JA, Dijkstra J, Kuik DJ, Van den Brekel MWM, Snow GB, Brakenhoff RH (2004) Molecular diagnosis of surgical margins and survival of patients with head and neck cancer. Clin Cancer Res 10:3614-3620

4. Rodrigo JP, Ferlito A, Suárez C, Shaha AR, Silver CE, Devaney KO, Bradley PJ, Bocker JM, McLaren KM, Grénman R, Rinaldo A (2005) New molecular diagnostic methods in head and neck cancer. Head Neck 27:995-1003

5. Bremmer JF, Graveland AP, Brink A, Braakhuis BJ, Kuik DJ, Leemans CR, Bloemena E, van der Waal I, Brakenhoff RH (2009) Screening for oral precancer with noninvasive genetic cytology. Cancer Prev Res (Phila Pa) 2:128-133

6. Lipshutz RJ, Fodor SP, Gingeras TR, Lockhart DJ (1999) High density synthetic oligonucleotide arrays. Nat Genet 21(1 Suppl):20-24

7. Diamandis EP (2004) Mass spectrometry as a diagnostic and a cancer biomarker discovery tool: opportunities and potential limitations. Mol Cell Proteomics 3:367-378

8. Li Y, Elashoff D, Oh M, Sinha U, St John MA, Zhou X, Abemayor E, Wong DT (2006) Serum circulating human mRNA profiling and its utility for oral cancer detection. J Clin Oncol 24:1754-1760

9. Nagaraj NS (2009) Evolving 'omics' technologies for diagnostics of head and neck cancer. Brief Funct Genomic Proteomic 8:49-59

10. Ferlito A, Rinaldo A, Robbins KT, Leemans CR, Shah JP, Shaha AR, Andersen PE, Kowalski LP, Pellitteri PK, Clayman GL, Rogers SN, Medina JE, Byers RM (2003) Changing concepts in the surgical management of the cervical node metastasis. Oral Oncol 39:429-435

11. Takes RP (2004) Staging of the neck in patients with head and neck squamous cell cancer: imaging techniques and biomarkers. Oral Oncol 40:656-667

12. van Wilgen CP, Dijkstra PU, van der Laan BF, Plukker JT, Roodenburg JL (2004) Shoulder complaints after nerve sparing neck dissections. Int J Oral Maxillofac Surg 33:253-257

13. Pentenero M, Gandolfo S, Carrozzo M (2005) Importance of tumor thickness and depth of invasion in nodal involvement and prognosis of oral squamous cell carcinoma: a review of the literature. Head Neck 27:1080-1091

14. Suzuki M, Suzuki T, Asai M, Ichimura K, Nibu K, Sugasawa M, Kaga K (2007) Clinicopathological factors related to cervical lymph node metastasis in a patient with carcinoma of the oral floor. Acta Otolaryngol Suppl 559:129-135 
15. Alkureishi LW, Ross GL, Shoaib T, Soutar DS, Robertson AG, Sorensen JA, Thomsen J, Krogdahl A, Alvarez J, Barbier L, Santamaria J, Poli T, Sesenna E, Kovács AF, Grünwald F, Barzan L, Sulfaro S, Alberti F (2008) Does tumor depth affect nodal upstaging in squamous cell carcinoma of the head and neck? Laryngoscope 118:629-634

16. Jung J, Cho NH, Kim J, Choi EC, Lee SY, Byeon HK, Park YM, Yang WS, Kim SH (2009) Significant invasion depth of early oral tongue cancer originated from the lateral border to predict regional metastases and prognosis. Int J Oral Maxillofac Surg 38:653-660

17. Takes RP, Rinaldo A, Rodrigo JP, Devaney KO, Fagan JJ, Ferlito A (2008) Can biomarkers play a role in the decision about treatment of the clinically negative neck in patients with head and neck cancer? Head Neck 30:525-538

18. Rinaldo A, Devaney KO, Ferlito A (2004) Immunohistochemical studies in the identification of lymph node micrometastases in patients with squamous cell carcinoma of the head and neck. ORL J Otorhinolaryngol Relat Spec 66:38-41

19. Yoshida K, Kashima K, Suenaga S, Nomi N, Shuto J, Suzuki M (2005) Immunohistochemical detection of cervical lymph node micrometastases from T2N0 tongue cancer. Acta Otolaryngol 125:654-658

20. Becker MT, Shores CG, Yu KK, Yarbrough WG (2004) Molecular assay to detect metastatic head neck squamous cell carcinoma. Arch Otolaryngol Head Neck Surg 130:21-27

21. Cote RJ, Peterson HF, Chaiwun B, Gelber RD, Goldhirsch A, Castiglione-Gertsch M, Gusterson B, Neville AM (1999) Role of immunohistochemical detection of lymph-node metastases in management of breast cancer. International Breast Cancer Study Group. Lancet 354:896-900

22. Elsheikh MN, Mahfouz ME, Elsheikh E (2005) Level IIb lymph nodes metastasis in elective supraomohyoid neck dissection for oral cavity squamous cell carcinoma: a molecular-based study. Laryngoscope 115:1636-1640

23. Elsheikh MN, Mahfouz ME, Salim EI, Elsheikh EA (2006) Molecular assessment of neck dissections supports preserving level IIB lymph nodes in selective neck dissection for laryngeal squamous cell carcinoma with a clinically negative neck. ORL J Otorhinolaryngol Relat Spec 68:177-184

24. Shores CG, Yin X, Funkhouser W, Yarbrough W (2004) Clinical evaluation of a new molecular method for detection of micrometastases in head and neck squamous cell carcinoma. Arch Otolaryngol Head Neck Surg 130:937-942

25. Yamazaki Y, Chiba I, Hirai A, Satoh C, Sakakibara N, Notani K, Iizuka T, Totsuka Y (2005) Clinical value of genetically diagnosed lymph node micrometastasis for patients with oral squamous cell carcinoma. Head Neck 27:676-681

26. Nieuwenhuis EJ, Jaspars LH, Castelijns JA, Bakker B, Wishaupt RG, Denkers F, Leemans CR, Snow GB, Brakenhoff RH (2003) Quantitative molecular detection of minimal residual head and neck cancer in lymph node aspirates. Clin Cancer Res 9:755-761

27. Colnot DR, Nieuwenhuis EJC, Kuik DJ, Leemans CR, Dijkstra J, Snow GB, Van Dongen GAMS, Brakenhoff RH (2004) Clinical significance of micrometastatic cells detected by E48 (Ly-6D) reverse transcriptase-polymerase chain reaction in bone marrow of head and neck cancer patients. Clin Cancer Res 10:7827-7833

28. Tsujimoto M, Nakabayashi K, Yoshidome K, Kaneko T, Iwase T, Akiyama F, Kato Y, Tsuda H, Ueda S, Sato K, Tamaki Y, Noguchi S, Kataoka TR, Nakajima H, Komoike Y, Inaji H, Tsugawa K, Suzuki K, Nakamura S, Daitoh M, Otomo Y, Matsuura N (2007) One-step nucleic acid amplification for intraoperative detection of lymph node metastasis in breast cancer patients. Clin Cancer Res 13:4807-4816

29. Ferris RL, Xi L, Raja S, Hunt JL, Wang J, Gooding WE, Kelly L, Ching J, Luketich JD, Godfrey TE (2005) Molecular staging of cervical lymph nodes in squamous cell carcinoma of the head and neck. Cancer Res 65:2147-2156

30. Goda H, Nakashiro K, Yoshimura T, Sumida T, Wakisaka H, Hato N, Hyodo M, Hamakawa H (2009) One-step nucleic acid amplification for detecting lymph node metastasis of head and neck cancer. J Clin Oncol 27:15s

31. Takes RP, Baatenburg de Jong RJ, Schuuring E, Hermans J, Vis AA, Litvinov SV, van Krieken JHJM (1997) Markers for assessment of nodal metastases in laryngeal carcinoma. Arch Otolaryngol Head Neck Surg 123:412-419

32. Germani RM, Civantos FJ, Elgart G, Roberts B, Franzmann EJ (2009) Molecular markers of micrometastasis in oral cavity carcinomas. Otolaryngol Head Neck Surg 141:52-58

33. Chung CH, Parker JS, Karaca G, Wu J, Funkhouser WK, Moore D, Butterfoss D, Xiang D, Zanation A, Yin X, Shockley WW, Weissler MC, Dressler LG, Shores CG, Yarbrough WG, Perou CM (2004) Molecular classification of head and neck squamous cell carcinomas using patterns of gene expression. Cancer Cell 5:489-500

34. Roepman P, Wessels LFA, Kettelarij N, Kemmeren P, Miles AJ, Lijnzaad P, Tilanus MGJ, Koole R, Hordijk G-J, van der Vliet PC, Reinders MJT, Slootweg PJ, Holstege FCP (2005) An expression profile for diagnosis of lymph node metastases from primary head and neck squamous cell carcinomas. Nat Genet $37: 182-186$

35. Woolgar JA (1999) Pathology of the N0 neck. Br J Oral Maxillofac Surg 37:205-209

36. Robbins KT, Clayman G, Levine PA, Medina J, Sessions R, Shaha A, Som P, Wolf GT, American Head and Neck Society, American Academy of Otolaryngology-Head and Neck Surgery (2002) Neck dissection classification update: revisions proposed by the American Head and Neck Society and the American Academy of Otolaryngology-Head and Neck Surgery. Arch Otolaryngol Head Neck Surg 128:751-758

37. Roepman P, Kemmeren P, Wessels LFA, Slootweg PJ, Holstege FC (2006) Multiple robust signatures for detecting lymph node metastasis in head and neck cancer. Cancer Res 66:2361-2366

38. Michiels S, Koscielny S, Hill C (2005) Prediction of cancer outcome with microarrays: a multiple random validation strategy. Lancet 365:488-492

39. Simon R, Radmacher MD, Dobbin K, McShane LM (2003) Pitfalls in the use of DNA microarray data for diagnostic and prognostic classification. J Natl Cancer Inst 95:14-18

40. Cromer A, Carles A, Millon R, Ganguli G, Chalmel F, Lemaire F, Young J, Dembélé D, Thibault C, Muller D, Poch O, Abecassis J, Wasylyk B (2004) Identification of genes associated with tumorigenesis and metastatic potential of hypopharyngeal cancer by microarray analysis. Oncogene 23:2484-2498

41. O’Donnell RK, Kupferman M, Wei SJ, Singhal S, Weber R, O'Malley B, Cheng Y, Putt M, Feldman M, Ziober B, Muschel RJ (2005) Gene expression signature predicts lymphatic metastasis in squamous cell carcinoma of the oral cavity. Oncogene 24:1244-1251

42. Schmalbach CE, Chepeha DB, Giordano TJ, Rubin MA, Teknos TN, Bradford CR, Wolf GT, Kuick R, Misek DE, Trask DK, Hanash S (2004) Molecular profiling and the identification of genes associated with metastatic oral cavity/pharynx squamous cell carcinoma. Arch Otolaryngol Head Neck Surg 130:295-302

43. Colella S, Richards KL, Bachinski LL, Baggerly KA, Tsavachidis S, Lang JC, Schuller DE, Krahe R (2008) Molecular signatures of metastasis in head and neck cancer. Head Neck 30:1273-1283

44. Akervall J (2006) Genomic screening of head and neck cancer and its implications for therapy planning. Eur Arch Otorhinolaryngol 263:297-304

45. Smeets SJ, Brakhuis BJM, Abbas S, Snijders PJ, Ylstra B, van de Wiel MA, Meijer GA, Leemans CR, Brakenhoff RH (2006) 
Genome-wide DNA copy number alterations in head and neck squamous cell carcinomas with or without oncogene-expressing human papillomavirus. Oncogene 25:2558-2564

46. Wang Y, Klijn JG, Zhang Y, Sieuwerts AM, Look MP, Yang F, Talantov D, Timmermans M, Meijer-van Gelder ME, Yu J, Jatkoe T, Berns EM, Atkins D, Foekens JA (2005) Gene-expression profiles to predict distant metastasis of lymph-node-negative primary breast cancer. Lancet 365:671-679

47. Foekens JA, Atkins D, Zhang Y, Sweep FC, Harbeck N, Paradiso A, Cufer T, Sieuwerts AM, Talantov D, Span PN, Tjan-Heijnen VC, Zito AF, Specht K, Hoefler H, Golouh R, Schittulli F, Schmitt M, Beex LV, Klijn JG, Wang Y (2006) Multicenter validation of a gene expression-based prognostic signature in lymph node-negative primary breast cancer. J Clin Oncol 24:1665-1671

48. Osman I, Sherman E, Singh B, Venkatraman E, Zelefsky M, Bosl G, Scher H, Shah J, Shaha A, Kraus D, Cordon-Cardo C, Pfister DG (2002) Alteration of p53 pathway in squamous cell carcinoma of the head and neck: impact on treatment outcome in patients treated with larynx preservation intent. J Clin Oncol 20:2980-2987

49. Bradford CR, Zhu S, Ogawa H, Ogawa T, Ubell M, Narayan A, Johnson G, Wolf GT, Fisher SG, Carey TE (2003) P53 mutation correlates with cisplatin sensitivity in head and neck squamous cell carcinoma lines. Head Neck 25:654-661

50. Ganly I, Talbot S, Carlson D, Viale A, Maghami E, Osman I, Sherman E, Pfister D, Chuai S, Shaha AR, Kraus D, Shah JP, Socci ND, Singh B (2007) Identification of angiogenesis/ metastases genes predicting chemoradiotherapy response in patients with laryngopharyngeal carcinoma. J Clin Oncol 25:1369-1376

51. Bockmühl U, Schlüns K, Küchler I, Petersen S, Petersen I (2000) Genetic imbalances with impact on survival in head and neck cancer patients. Am J Pathol 157:369-375

52. Ashman JN, Patmore HS, Condon LT, Cawkwell L, Stafford ND, Greenman J (2003) Prognostic value of genomic alterations in head and neck squamous cell carcinoma detected by comparative genomic hybridisation. Br J Cancer 89:864-869

53. Wreesmann VB, Shi W, Thaler HT, Poluri A, Kraus DH, Pfister D, Shaha AR, Shah JP, Rao PH, Singh B (2004) Identification of novel prognosticators of outcome in squamous cell carcinoma of the head and neck. J Clin Oncol 22:3965-3972

54. Rodrigo JP, García LA, Ramos S, Lazo PS, Suárez C (2000) EMS1 gene amplification correlates with poor prognosis in squamous cell carcinomas of the head and neck. Clin Cancer Res 6:3177-3182

55. Huang X, Gollin SM, Raja S, Godfrey TE (2002) High-resolution mapping of the 11q13 amplicon and identification of a gene, TAOS1, that is amplified and overexpressed in oral cancer cells. Proc Natl Acad Sci USA 99:11369-11374

56. Rodrigo JP, García-Carracedo D, García LA, Menéndez S, Allonca E, González MV, Fresno MF, Suárez C, García-Pedrero JM (2009) Distinctive clinicopathological associations of amplification of the cortactin gene at 11q13 in head and neck squamous cell carcinomas. J Pathol 217:516-523

57. Gibcus JH, Menkema L, Mastik MF, Hermsen MA, de Bock GH, van Velthuysen ML, Takes RP, Kok K, Alvarez Marcos CA, van der Laan BF, van den Brekel MW, Langendijk JA, Kluin PM, van der Wal JE, Schuuring E (2007) Amplicon mapping and expression profiling identify the Fas-associated death domain gene as a new driver in the 11q13.3 amplicon in laryngeal/pharyngeal cancer. Clin Cancer Res 13:6257-6266

58. Brass N, Heckel D, Sahin U, Pfreundschuh M, Sybrecht GW, Meese E (1997) Translation initiation factor eIF-4 gamma is encoded by an amplified gene and induces an immune response in squamous cell lung carcinoma. Hum Mol Genet 6:33-39
59. Singh B, Reddy PG, Goberdhan A, Walsh C, Dao S, Ngai I, Chou TC, O-Charoenrat P, Levine AJ, Rao PH, Stoffel A (2002) p53 regulates cell survival by inhibiting PIK3CA in squamous cell carcinomas. Genes Dev 16:984-993

60. Eder AM, Sui X, Rosen DG, Nolden LK, Cheng KW, Lahad JP, Kango-Singh M, Lu KH, Warneke CL, Atkinson EN, Bedrosian I, Keyomarsi K, Kuo WL, Gray JW, Yin JC, Liu J, Halder G, Mills GB (2005) Atypical PKCiota contributes to poor prognosis through loss of apical-basal polarity and cyclin E overexpression in ovarian cancer. Proc Natl Acad Sci USA 102:12519-12524

61. Kanao H, Enomoto T, Kimura T, Fujita M, Nakashima R, Ueda Y, Ueno Y, Miyatake T, Yoshizaki T, Buzard GS, Tanigami A, Yoshino K, Murata Y (2005) Overexpression of LAMP3/ TSC403/DC-LAMP promotes metastasis in uterine cervical cancer. Cancer Res 65:8640-8645

62. Regala RP, Weems C, Jamieson L, Copland JA, Thompson EA, Fields AP (2005) Atypical protein kinase Ciota plays a critical role in human lung cancer cell growth and tumorigenicity. J Biol Chem 280:31109-31115

63. Singh B, Pfister DG (2008) Individualized treatment selection in patients with head and neck cancer: do molecular markers meet the challenge? J Clin Oncol 26:3114-3116

64. Slebos RJ, Yi Y, Ely K, Carter J, Evjen A, Zhang X, Shyr Y, Murphy BM, Cmelak AJ, Burkey BB, Netterville JL, Levy S, Yarbrough WG, Chung CH (2006) Gene expression differences associated with human papillomavirus status in head and neck squamous cell carcinoma. Clin Cancer Res 12:701-709

65. Smeets SJ, Brakenhoff RH, Ylstra B, van Wieringen WN, van de Wiel MA, Leemans CR, Braakhuis BJM (2009) Genetic classification of oral and oropharyngeal carcinomas identifies subgroups with a different prognosis. Cell Oncol 31:291-300

66. Sidransky D (1997) Nucleic acid-based methods for the detection of cancer. Science 278:1054-1059

67. Boyle JO, Mao L, Brennan JA, Koch WM, Eisele DW, Saunders JR, Sidransky D (1994) Gene mutations in saliva as molecular markers for head and neck squamous cell carcinomas. Am J Surg 168:429-432

68. Mao L, Lee DJ, Tockman MS, Erozan YS, Askin F, Sidransky D (1994) Microsatellite alterations as clonal markers for the detection of human cancer. Proc Natl Acad Sci USA 91:98719875

69. Nawroz H, Koch W, Anker P, Stroun M, Sidransky D (1996) Microsatellite alterations in serum DNA of head and neck cancer patients. Natl Med 2:1035-1037

70. Park NJ, Zhou X, Yu T, Brinkman BM, Zimmermann BG, Palanisamy V, Wong DT (2007) Characterization of salivary RNA by cDNA library analysis. Arch Oral Biol 52:30-35

71. Park NJ, Zhou H, Elashoff D, Henson BS, Kastratovic DA, Abemayor E, Wong DT (2009) Salivary microRNA: discovery, characterization, and clinical utility for oral cancer detection. Clin Cancer Res 15:5473-5477

72. Hu S, Arellano M, Boontheung P, Wang J, Zhou H, Jiang J, Elashoff D, Wei R, Loo JA, Wong DT (2008) Salivary proteomics for oral cancer biomarker discovery. Clin Cancer Res $14: 6246-6252$

73. Garber K (2004) Genomic medicine: gene expression tests foretell breast cancer's future. Science 303:1754-1755

74. Kallioniemi O (2004) Medicine: profile of a tumour. Nature 428:379-382

75. van't Veer LJ, Dai H, van de Vijver MJ, He YD, Hart AA, Mao M, Peterse HL, van der Kooy K, Marton MJ, Witteveen AT, Schreiber GJ, Kerkhoven RM, Roberts C, Linsley PS, Bernards R, Friend SH (2002) Gene expression profiling predicts clinical outcome of breast cancer. Nature 415:530-536

76. Ma XJ, Wang Z, Ryan PD, Isakoff SJ, Barmettler A, Fuller A, Muir B, Mohapatra G, Salunga R, Tuggle JT, Tran Y, Tran D, 
Tassin A, Amon P, Wang W, Wang W, Enright E, Stecker K, Estepa-Sabal E, Smith B, Younger J, Balis U, Michaelson J, Bhan A, Habin K, Baer TM, Brugge J, Haber DA, Erlander MG, Sgroi DC (2004) A two-gene expression ratio predicts clinical outcome in breast cancer patients treated with tamoxifen. Cancer Cell 5:607-616

77. Ramaswamy S, Ross KN, Lander ES, Golub TR (2003) A molecular signature of metastasis in primary solid tumors. Nat Genet 33:49-54

78. Caldas C, Aparicio SA (2002) The molecular outlook. Nature 415:484-485
79. van't Veer LJ, Bernards R (2008) Enabling personalized cancer medicine through analysis of gene-expression patterns. Nature 452:564-570

80. Reid JF, Lusa L, De Cecco L, Coradini D, Veneroni S, Daidone MG, Gariboldi M, Pierotti MA (2005) Limits of predictive models using microarray data for breast cancer clinical treatment outcome. J Natl Cancer Inst 97:927-930

81. Dunkler D, Michiels S, Schemper M (2007) Gene expression profiling: does it add predictive accuracy to clinical characteristics in cancer prognosis? Eur J Cancer 43:745-751 